\title{
Study of Process Parameters for Making Biodegradable Linear Low Density Polyethylene in Natural Weathering Conditions
}

\author{
Dr. Ruhul Amin ${ }^{1}$, Dr. Dil Afroza Begum ${ }^{1}$, Dr. Abdul Gafur ${ }^{2}$ \\ ${ }^{I}$ Professor, Department of Chemical Engineering Department, BUET, Dhaka-1000 \\ ${ }^{2}$ Senior Scientific Officer, PP \& PDC, BCSIR, Dhaka
}

\begin{abstract}
The Objective of this project was to develop biodegradable and environmentally friendly polymers using starch blended with polyethylene (PE) by extrusion where starch content ranged between 0 and $15 \%$. The samples of varying compositions were molded into plates and films. A portion of the specimens were exposed to sunlight and the rest buried underground. The deterioration of the starch-polyethlene composites following exposure was determined by measuring changes in tensile properties, flexural properties, SEM imaging and FTIR analysis of the samples. The mechanical properties of these samples were assessed to determine their feasibility as a packaging material. It was found that the addition of starch to the polyethylene decreases its tensile strength. Young's modulus increased as a function of the amount of starch. Chemical structure was found degraded. Rate of degradation was different. Samples become very brittle and lose its strength within one month of exposure. SEM analysis revealed fractures and pores as a consequence of microorganism degradation. Pure PE samples however remained unchanged.
\end{abstract}

Keywords: Biodegradable, starch, polyethylene (PE), environment friendly

\subsection{Plastics Biodegradation}

\section{Introduction}

Biodegradation is the chemical breakdown of materials accompanied by a loss in molecular weight by a physiological environment. Organic materials can be degraded aerobically with oxygen or anaerobically, without oxygen. Bio surfactant, an extracellular surfactant secreted by microorganisms, also enhances the biodegradation process.

Biodegradable polymers can be classified into 2 main types:

1. Hydro-biodegradable plastics (HBP)

2. Oxo-biodegradable plastics (OBP)

Both will undergo degradation by hydrolysis and oxidation respectively, the end products being carbon dioxide, water and biomass. OBP does not degrade quickly i.e. it releases its carbon slowly, thus, producing high quality compost. It is bio assimilated by bacteria and fungi which transform the degraded plastic products to cell biomass. They are also designed to be able to subject to photo-oxidation and thermo-oxidation. OBPs are usually made by adding small proportions of specific transition metals into original synthesis.

HBPs tend to degrade quickly than OBP but have to be collected and put into industrial composting unit. HBPs emit methane in anaerobic conditions but OBP does not. Biodegradation is measured in various ways, namely, the amount of oxygen consumed by aerobic microbes or the amount of carbon dioxide produced. For anaerobic microbes, it may be measured by amount of biomass or methane produced.

The properties of plastics are associated with their biodegradability. Both the chemical and physical properties of plastics influence the mechanism of biodegradation. The surface conditions (surface area, hydrophilic, and hydrophobic properties), the first order structures (chemical structure, molecular weight and molecular weight distribution) and the high order structures (glass transition temperature, melting temperature, modulus of elasticity, crystallinity and crystal structure) of polymers play important roles in the biodegradation processes.

In general, polyesters with side chains are less assimilated than those without side chains. The molecular weight is also important for the biodegradability because it determines many physical properties of the polymer. Increasing the molecular weight of the polymer decreased its degradability. Moreover, the morphology of polymers greatly affects their rates of biodegradation. The degree of crystallinity is a crucial factor affecting biodegradability, since enzymes mainly attack the amorphous domains of a polymer. The molecules in the amorphous region are loosely packed, and thus make it more susceptible to degradation. The crystalline part of the polymers is more resistant than the amorphous region. (Yutaka Tokiwa, 2009) 


\subsection{Biodiversity and Occurrence of Polymer-Degrading Microorganisms}

Biodiversity and occurrence of polymer-degrading microorganisms vary depending on the environment, such as soil, sea, compost, activated sludge, etc. It is necessary to investigate the distribution and population of polymer-degrading microorganisms in various ecosystems. Generally, the adherence of microorganisms on the surface of plastics followed by the colonization of the exposed surface is the major mechanisms involved in the microbial degradation of plastics. Some microorganisms have the astonishing, naturally occurring, microbial catabolic diversity to degrade, transform or accumulate a huge range of compounds including hydrocarbons (e.g. oil), polychlorinated biphenyls (PCBs), polyaromatic hydrocarbons (PAHs), pharmaceutical substances, radionuclides and metals. Major methodological breakthroughs in microbial biodegradation have enabled detailed genomic, metagenomic, proteomic, bioinformatic and other highthroughput analyses of environmentally relevant microorganisms providing unprecedented insights into key biodegradative pathways and the ability of microorganisms to adapt to changing environmental conditions. The enzymatic degradation of plastics by hydrolysis is a two-step process: first, the enzyme binds to the polymer substrate then subsequently catalyzes a hydrolytic cleavage. Polymers are degraded into low molecular weight oligomers, dimers and monomers and finally mineralized to $\mathrm{CO}_{2}$ and $\mathrm{H}_{2} \mathrm{O}$. (Yutaka Tokiwa, 2009)

\subsection{Starch-based polymers}

Thermoplastic starches are based on gelatinized starch from different sources, for example, potato, corn, wheat or tapioca. With the use of specific plasticizing solvents can be converted into thermoplastic materials with good performance properties and with inherent biodegradability. Most importantly, thermoplastic starch compounds can be processed on existing plastics fabrication equipment. Three types of starch-based polymers have been developed (ExcelPlas, 2003). The first type consists of a synthetic polymer, usually polyethylene (PE), and the starch is only present as filler. These bags are not fully biodegradable and consist of mainly non-biodegradable synthetic polymers like polyethylene or polypropylene and only 5-50 percent starch. The starch biodegrades and the plastic disintegrates into small particles. Many manufacturers of starch based additives describe their product as being 'photo-biodegradable'. One example of a refined first type product is the Willow Ridge products such as PolyStarch N, a masterbatch of 55\% cornstarch with LLDPE. The product includes a processing aid and 3-10\% levels of a desiccant (trade-named Aquanil) that ensures moisture control prior to use. PolyStarch N is suitable for LDPE and LLDPE garbage bags, agricultural films, and injection and blow molded parts intended for disposal in conditions able to sustain microbes. In the second type, the thermoplastic starch is used as polymeric materials and not only as an additive. It is usually blended with hydrophilic synthetic polymers (e.g. polyester or polycaprolactone) and contributes to the strength of the material when used a percentage of 50-80\%. The third type is a truly biodegradable plastic that does not contain synthetic polymers at all. To improve some of the properties of the plastic, the starch is modified, but no synthetic material is necessary. An example of this type of polymer is Novon, which is starch (90-95\%) plus additives.

\subsection{Photodegradable polymers}

'Photodegradable polymers' are synthetic polymers incorporating light-sensitive chemical additives or copolymers for the purposes of weakening the bonds of the polymer in the presence of ultraviolet radiation (ExcelPlas, 2003). Photosensitizers used include diketones, ferrocene derivatives (aminoalkyferrocene) and carbonyl-containing species. A new approach to making photodegradable plastics is adding metal salts to initiate the breakdown process. Many photodegradable polymers are a combination of PE and controlled degradation master batch additives.

One of the manufacturers of these additives is Evergreen Environmental, a South African company, which developed an additive system that causes plastic litter to degrade rapidly into water and carbon dioxide in the outdoors under the influence of UV radiation. By introducing a prodegradant into plastic bag production, the life of the plastic bag is reduced which would ultimately reduce the build-up of litter in the environment. A second manufacturer is Willow Ridge (Willow Ridge, Erlanger, Ky.) which produces a master-batch that simultaneously triggers photodegradation and thermal-oxidative breakdown in PE. The product is typically used at a 3\% level (Leaversuch, 2002). Willow Ridge also supplies a photodegradable master-batch designated UV-H that accelerates UV degradation by creating free radicals that sever the polymer chains into smaller fragments that can be consumed by microbes.

\subsection{Materials}

\section{Methodology}

Materials utilized in this investigation include film grade low density polyethylene (dried at $65^{\circ} \mathrm{C}$ ), using film grade PE pellets. Reagent grade starch was used as the additive, dried before blending at $60-65^{\circ} \mathrm{C}$ in a vacuum dryer. 


\subsection{Sample Preparation}

\section{Sample Prepared by Scientific Grade Extruder}

The mixing with manually operated extruder was not homogeneous and hence a latest scientific grade extruder was used for blending to achieve uniform samples. By using the scientific grade extruder, the following compositions were prepared:

$0 \% \mathrm{~S}(100 \% \mathrm{PE})$

$5 \% \mathrm{~S}(95 \% \mathrm{PE})$

$10 \% \mathrm{~S}(90 \% \mathrm{PE})$

$15 \% \mathrm{~S}(85 \% \mathrm{PE})$

The blended composite polymers were cut into small pieces and kept in a mold to convert it into plates by using Paul-Otto Weber-presser Hydraulic Press machine.

Lastly, these plates were cut into dumbbell shaped specimens for mechanical property analysis.

By following the same procedure, for each composition 11 to 12 sets of plate samples were made.

\subsection{Sample Exposure for Biodegradability Study}

The degradability of the specimens outdoors was determined in this study by exposing them in sunlight and buried underground. The specimens were exposed for 200 days and samples were drawn at regular intervals and evaluated for degradation. The samples were kept outside for photo-degradation under ambient conditions (Fig.2) and some samples were buried underground at a depth of 4 to 5 inches beneath the soil for microbial degradation.

\subsection{Microanalysis}

In order to corroborate degradation, assay of the soil containing samples was studied in an Agar medium. The growth of microorganisms such as bacteria and fungi was checked at definite intervals of time. Samples of the soil $(\mathrm{N}=3)$ gave the following results.

Table 1: Microanalysis of Soil

\begin{tabular}{|c|c|}
\hline Test Parameters & Results \\
\hline Total Bacterial Count, cfu/g & $4.4 \times 105$ \\
\hline Total Yeast Count, cfu/g & $5.0 \times 102$ \\
\hline Total Mold Count, $\mathbf{c f u} / \mathbf{g}$ & $<10$ \\
\hline
\end{tabular}

\subsection{Biodegradation Studies}

\subsubsection{Physical Observation}

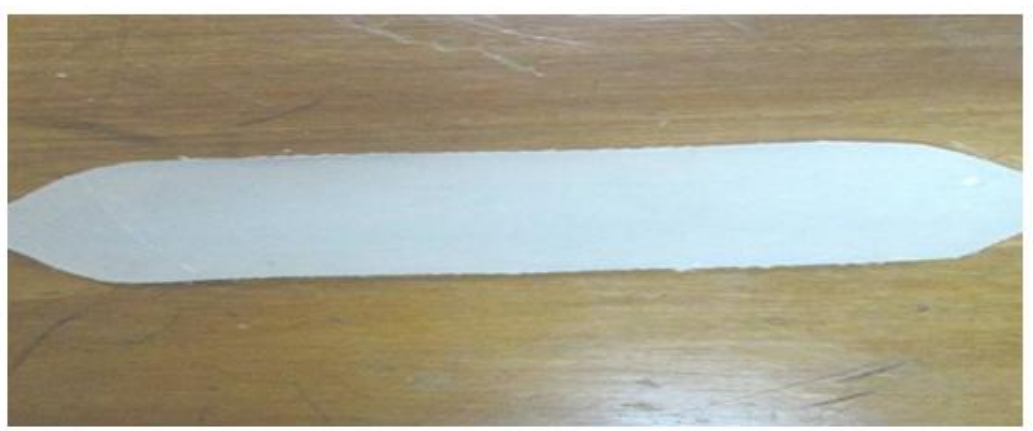

Figure 1: Sample before exposure

After exposure to the sunlight and burial underground, the samples turned brow/black. The surface also displayed roughness due to physical cracking.

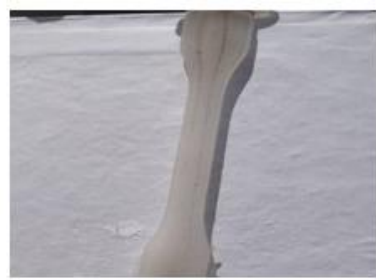

Figure 2: $0 \%$ Starch $+100 \%$ PE after 60 days

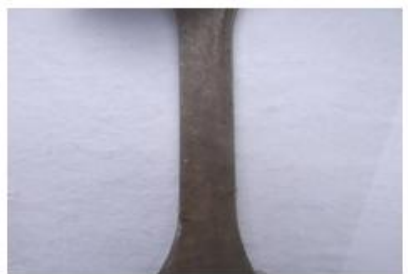

Figure 3: 5\% Starch + 95\% PE after 60 days 


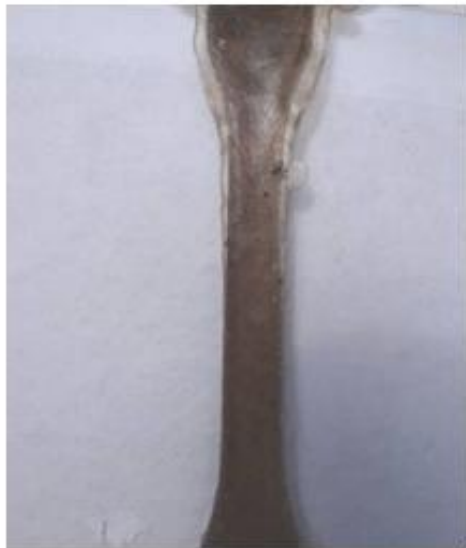

Figure 4: $10 \%$ Starch $+90 \%$ PE after 60 days.

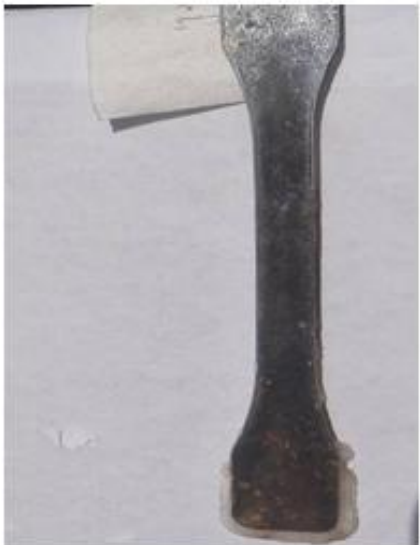

Figure 5: $15 \%$ Starch $+85 \%$ PE after 60 days.

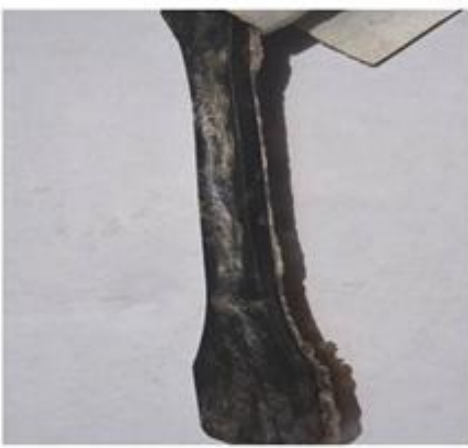

Figure 6: $20 \%$ Starch + 80\% PE after 60days

\subsubsection{Mechanical Strength Measurement}

Mechanical strength of the polymer samples were measured using the Universal Testing Machine (for Tensile and Flexural Strength). The prepared plates were cut into appropriate shapes to measure tensile strength. Before the samples were tested, the dimensions of samples were taken carefully. A minimum of three samples were tested for each formulation, and average values of the elongation to break, tensile strength, and elastic modulus were calculated. The elastic modulus was determined from the slope of the linear portion of the stressstrain curves; the tensile strength is the maximum load divided by the original cross-section area. The tensile and flexural strengths of the samples have been discussed in the next section.

\subsection{Mechanical properties}

The relationships between the compositions and mechanical properties, chemical properties and morphology of the samples have been shown and discussed below.

\section{Tensile properties:}

Table 2: Tensile Properties of test Samples

\begin{tabular}{|c|c|c|c|c|}
\hline Composition & Exposure time & Tensile Strength (MPa) & E-modulus (MPa) & Elongation \% \\
\hline \multirow{6}{*}{$\begin{array}{c}0 \% \\
\text { Starch sample }\end{array}$} & 1. 0 day & 10.83 & 189.9 & 108.9 \\
\hline & 2. 30 days & 10.48 & 229 & 55.8 \\
\hline & 3. 60 days & 10.10 & 256.9 & 33.56 \\
\hline & 4. $\quad 90$ days & 10.05 & 299.4 & 50.6 \\
\hline & 5. 150 days & 10.01 & 340.4 & 40.46 \\
\hline & 6. 200 days & 9.95 & 371.3 & 60.4 \\
\hline \multirow{6}{*}{$\begin{array}{c}5 \% \\
\text { Starch sample }\end{array}$} & 1. 0 day & 10.74 & 260 & 69.33 \\
\hline & 2. 30 days & 10.23 & 281 & 53.56 \\
\hline & 3. 60 days & 10.97 & 296 & 44.44 \\
\hline & 4. 90 days & 10.56 & 300.8 & 39.4 \\
\hline & 5. 150 days & 10.11 & 307.2 & 24.89 \\
\hline & 6. 200 days & 9.88 & 345.6 & 24.0 \\
\hline \multirow{4}{*}{$\begin{array}{c}10 \% \\
\text { Starch sample }\end{array}$} & 0 day & 10.34 & 276 & 22.22 \\
\hline & 2. 30 days & 10.21 & 274 & 18.56 \\
\hline & 3. 60 days & 10.63 & 275.8 & 15.87 \\
\hline & 4. $\quad 90$ days & 9.63 & 334 & 12.62 \\
\hline
\end{tabular}


Study of Process Parameters for Making Biodegradable Linear Low Density Polyethylene in Natural ..

\begin{tabular}{|c|cc|c|c|c|}
\hline & 5. & 150 days & 9.58 & 357.2 & 11.7 \\
\cline { 2 - 6 } & 6. & 200 days & 9.47 & 375.4 & 10.6 \\
\hline \multirow{4}{*}{$\begin{array}{c}\mathbf{1 5 \%} \\
\text { Starch sample }\end{array}$} & 1. & 0 day & 10.32 & 240 & 19.19 \\
\cline { 2 - 6 } & 2. & 30 days & 10.45 & 267 & 13.36 \\
\cline { 2 - 6 } & 3. & 60 days & 10.03 & 292.7 & 14.12 \\
\cline { 2 - 6 } & 4. & 90 days & 9.14 & 294 & 17.07 \\
\cline { 2 - 6 } & 5. & 150 days & 9.04 & 365 & 16.07 \\
\cline { 2 - 6 } & 6. & 200 days & 9.03 & & \\
\end{tabular}

Flexural properties:

Table 3: Flexural Properties of test Samples

\begin{tabular}{|c|c|c|c|c|}
\hline Composition & Exposure time (Day) & Flexural Strength (MPa) & E-modulus (MPa) & $\begin{array}{c}\text { Strain at max. } \\
\% \\
\end{array}$ \\
\hline \multirow{4}{*}{$\begin{array}{c}0 \% \\
\text { Starch -PE Sample }\end{array}$} & 2. 30 days & 7.71 & 403.9 & 4.013 \\
\hline & 4. 90 days & 5.88 & 250.8 & 3.807 \\
\hline & 5. 150 days & 3.39 & 424.9 & 3.088 \\
\hline & 6. 200 days & 3.20 & 352.8 & 2.106 \\
\hline \multirow{5}{*}{$\begin{array}{c}5 \% \\
\text { Starch-PE Sample }\end{array}$} & 2. 30 days & 9.34 & 427.3 & 4.055 \\
\hline & 3. 60 days & 9.74 & 498.8 & 4.424 \\
\hline & 4. 90 days & 8.06 & 216.2 & 3.384 \\
\hline & 5. 150 days & 7.12 & 495.2 & 3.184 \\
\hline & 6. 200 days & 5.48 & 1160 & 2.896 \\
\hline \multirow{3}{*}{$\begin{array}{c}10 \% \\
\text { Starch-PE Sample }\end{array}$} & 1. 0 day & 9.86 & 417.3 & 4.37 \\
\hline & 5. 150 days & 6.45 & 1088 & 2.773 \\
\hline & 6. 200 days & 5.14 & 1370 & 2.573 \\
\hline \multirow{6}{*}{$\begin{array}{c}15 \% \\
\text { Starch-PE Sample }\end{array}$} & 1. 0 day & 8.81 & 439 & 3.89 \\
\hline & 2. 30 days & 9.71 & 479.2 & 4.409 \\
\hline & 3. 60 days & 10.12 & 598 & 3.782 \\
\hline & 4. 90 days & 7.44 & 220.1 & 3.123 \\
\hline & 5. 150 days & 6.20 & 1335 & 2.007 \\
\hline & 6. 200 days & 5.48 & 1188 & 2.001 \\
\hline
\end{tabular}

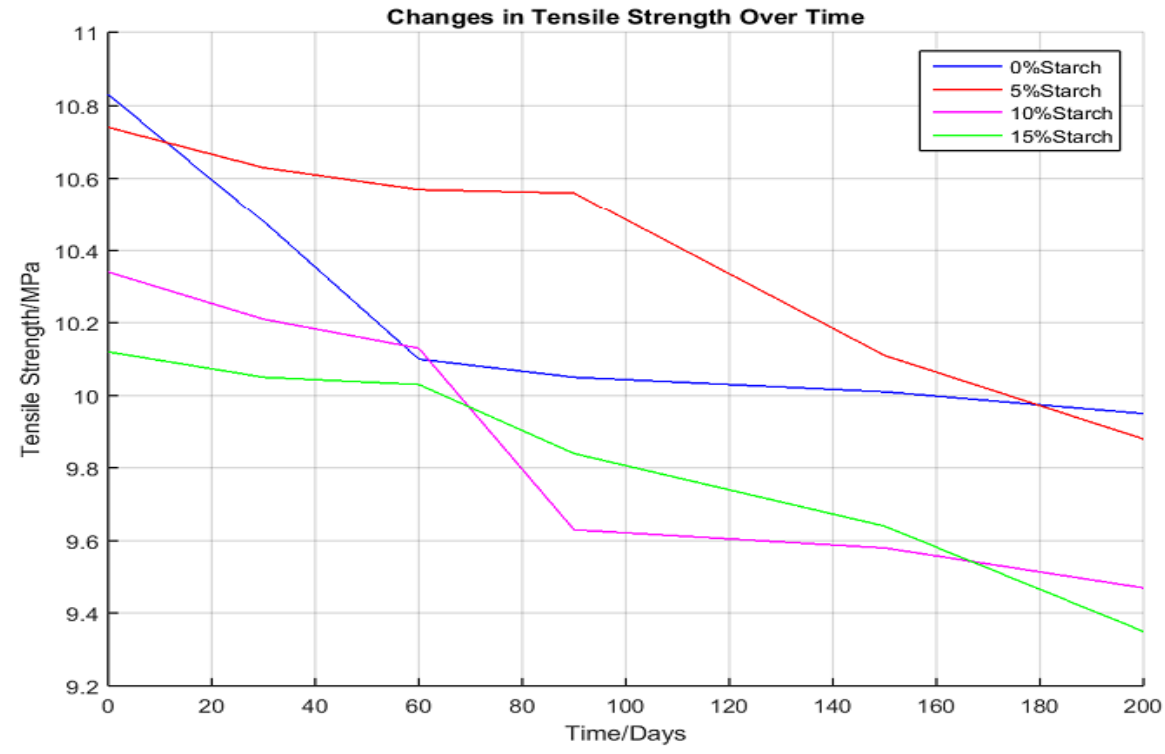

Figure 7: Relationship between Tensile Strength and composition with time 


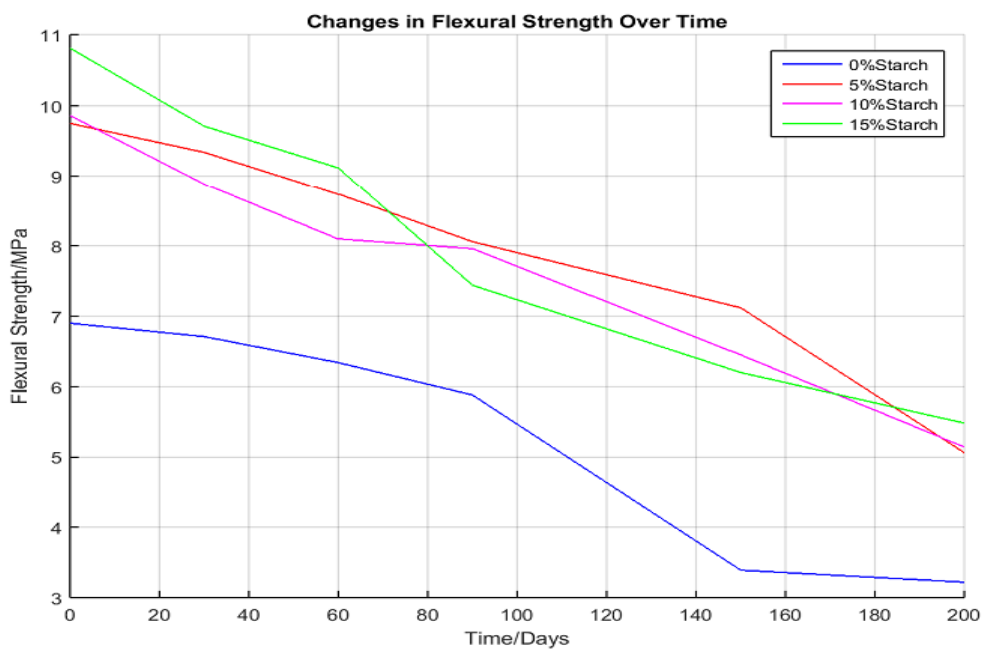

Figure 8: Relationship between Flexural Strength and composition with time

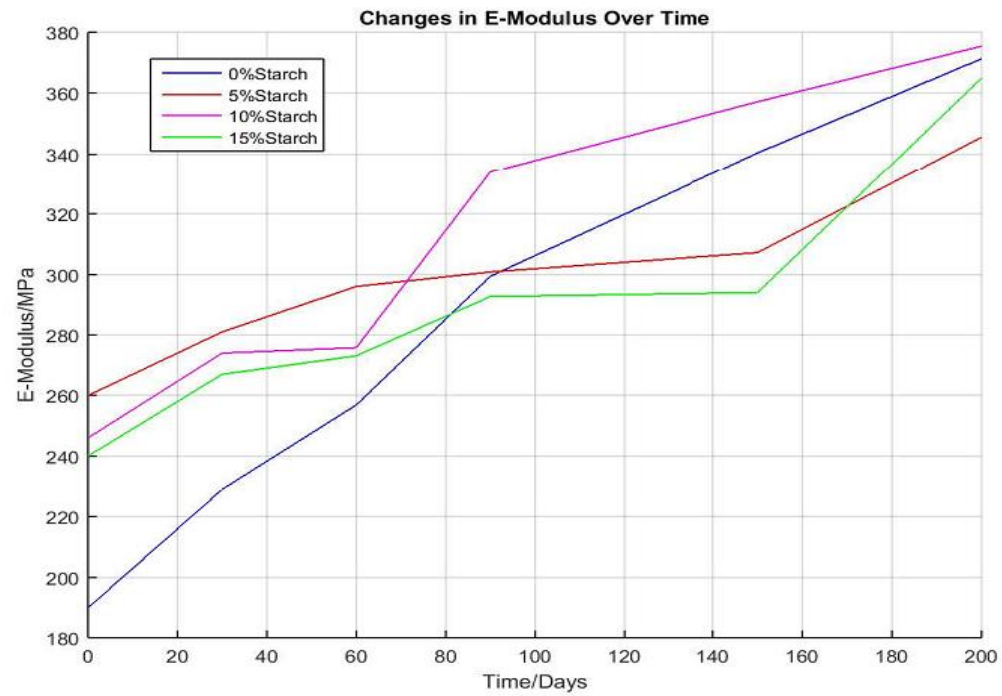

Figure 9: Relationship between E-Modulus and composition with time

The mechanical properties showed a progressive degradation with increase in starch content. Here it can be seen that on Day 0, as the amount of starch increases from 0 to $15 \%$ the tensile strength of the blend decreases from 10.83 $\mathrm{MPa}$ to $10.12 \mathrm{MPa}$. Elongation decreases from $108.9 \%$ to $19.19 \%$, measured for $0 \%$ Starch-PE and $15 \%$ Starch-PE, respectively.

More significant variation was observed for the blend having $15 \%$ Starch. This is because the additive used during the formulation has tensile properties much lower when compared to PE. Similar trends were observed for the LDPE/cassava starch blend by Nakamura et al. (Nakamura, 2005). Young's modulus for the specimens increased with the amount of starch. This can be explained by the crystallinity, hydrogen bonding and stiffening effect of the starch present in polystarch N (Chandra, Rustgi 1997).

\subsection{FTIR analysis}

Structural changes such as oxidation level of PE due to exposure to UV radiation (sunlight) can be accurately detected by FTIR. Spectra FTIR, for $0 \%$ starch, 5\% starch and 10\% starch at 0 day and after 30 days are given below: 


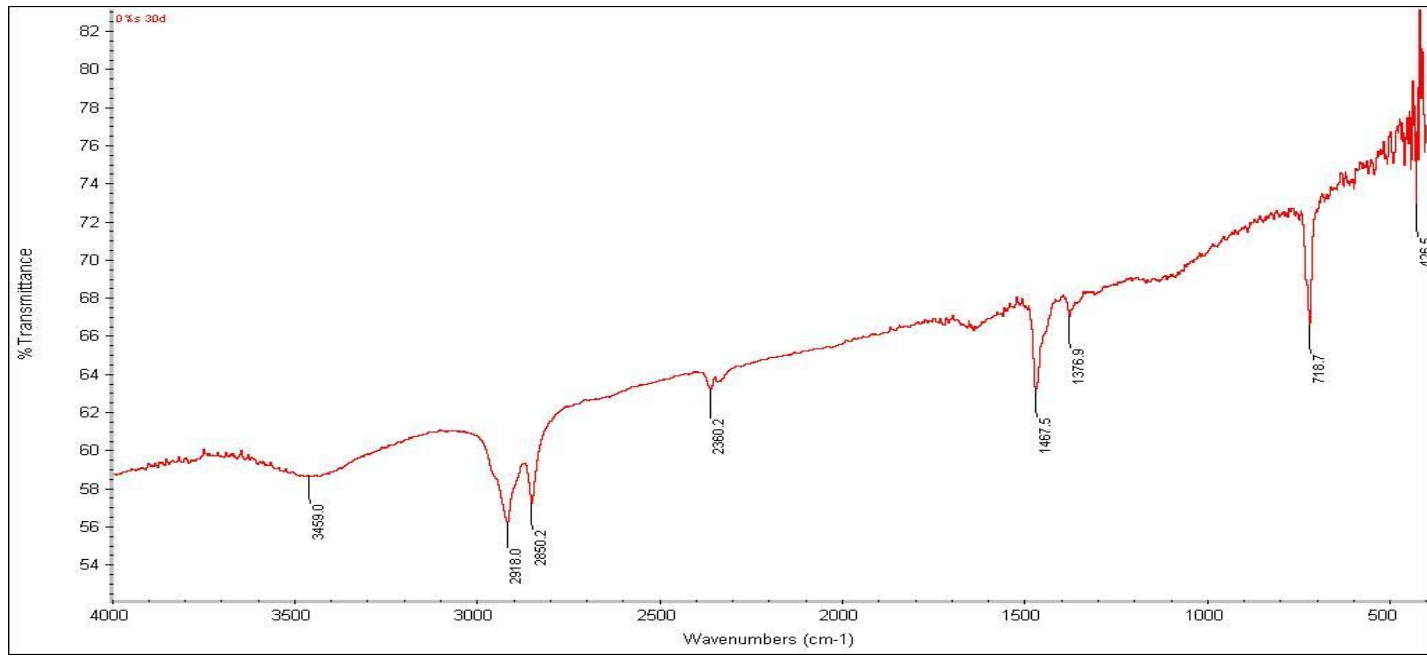

Figure 10: FTIR spectra for $0 \%$ starch at 0 day.

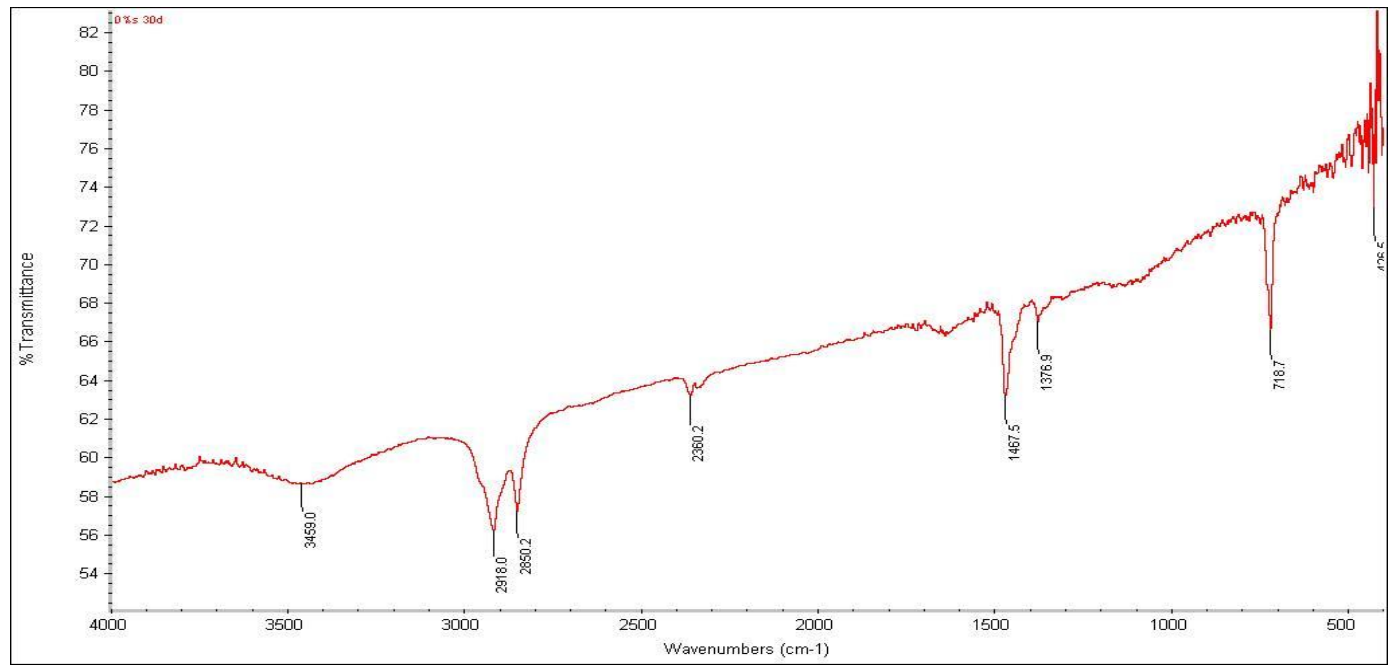

Figure 11: FTIR spectra for $0 \%$ starch after 30 days.

From the figure of FTIR spectra of $0 \%$ starch, it can be said that PE is not degraded after 30 days.

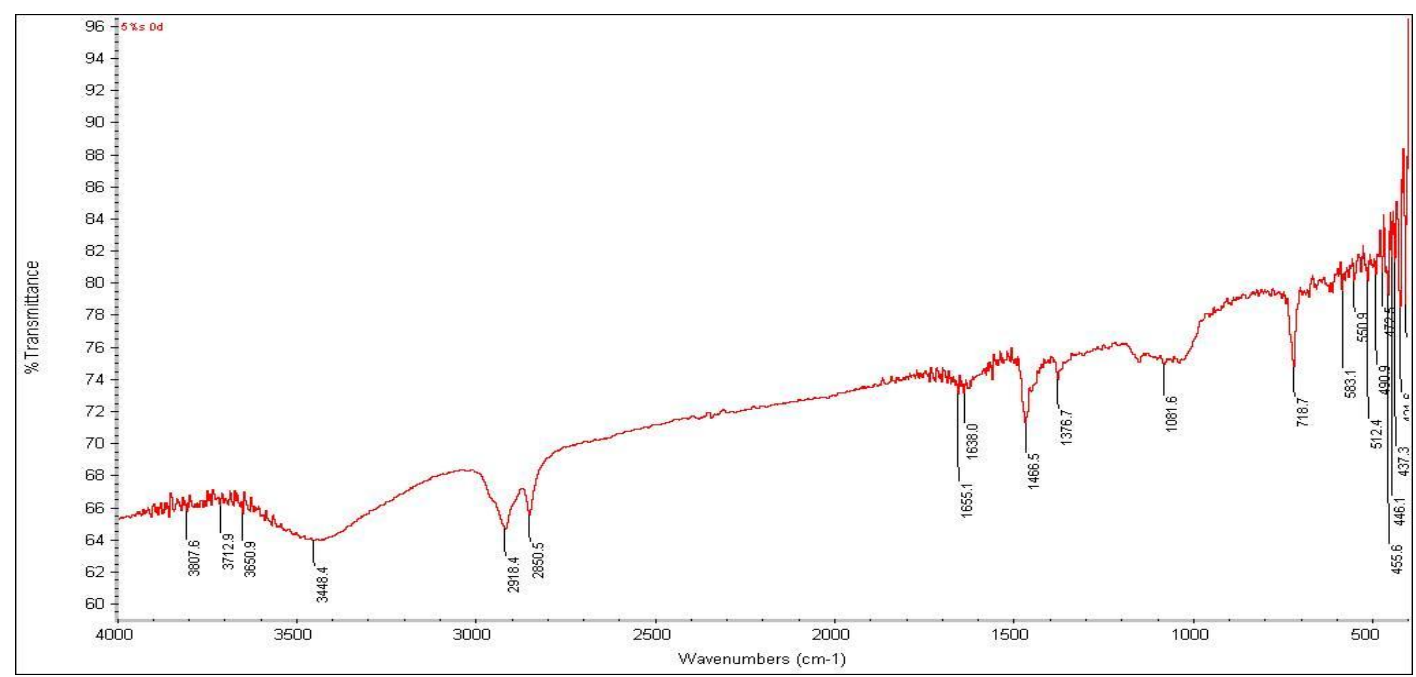

Figure 12: FTIR spectra for 5\% starch at Day 0 


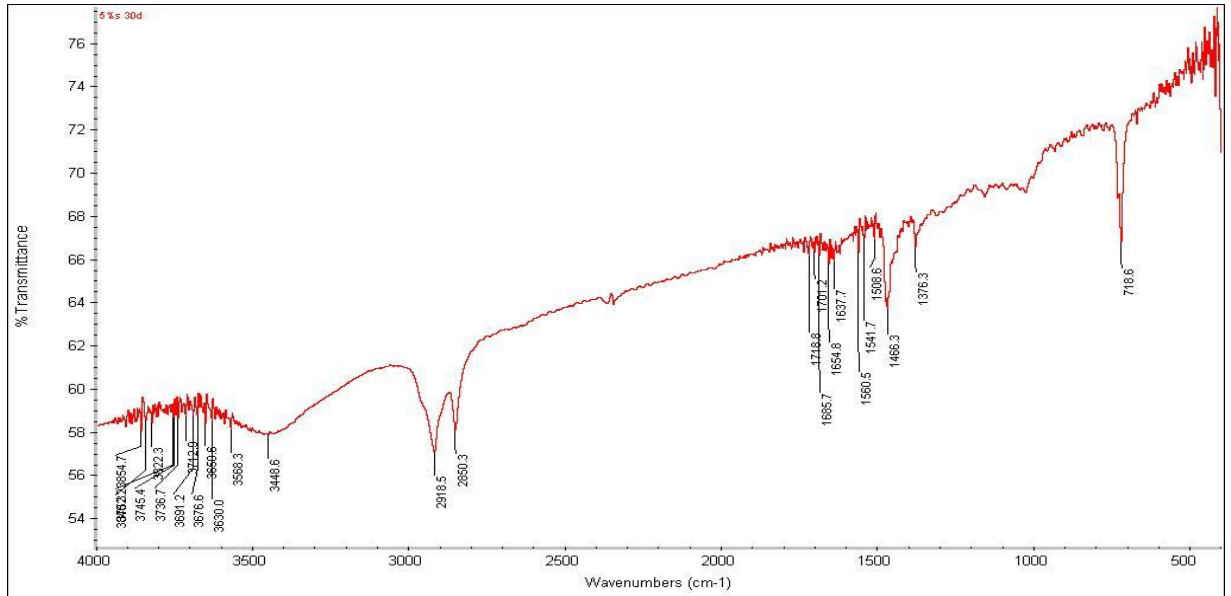

Figure 13 : FTIR spectra for $5 \%$ starch after 30 days

For 5\% Starch-PE, peaks are observed at 2917 and $2843 \mathrm{~cm}^{-1}$ corresponding to the vibration mode of $\mathrm{CH}_{2}$ group. The peak at $1715 \mathrm{~cm}^{-1}$ shows the band vibration of the $\mathrm{C}=\mathrm{O}$ group which appears due to the photooxidation of the PE. This band increases more considerably with time. The peak at $1463 \mathrm{~cm}^{-1}$ corresponds to the deformation and elongation mode of $\mathrm{CH}_{2}$ group (Gisjsman, 1997 and Allen, 2000). The FTIR spectra of the 5\% starch-PE sample also shows more peaks at 30 days than at Day 0 which indicates the degradation of the sample. Similar trends are found in the spectra of the $10 \%$ Starch-PE blend. A significant amount of peaks are seen after 30 days.

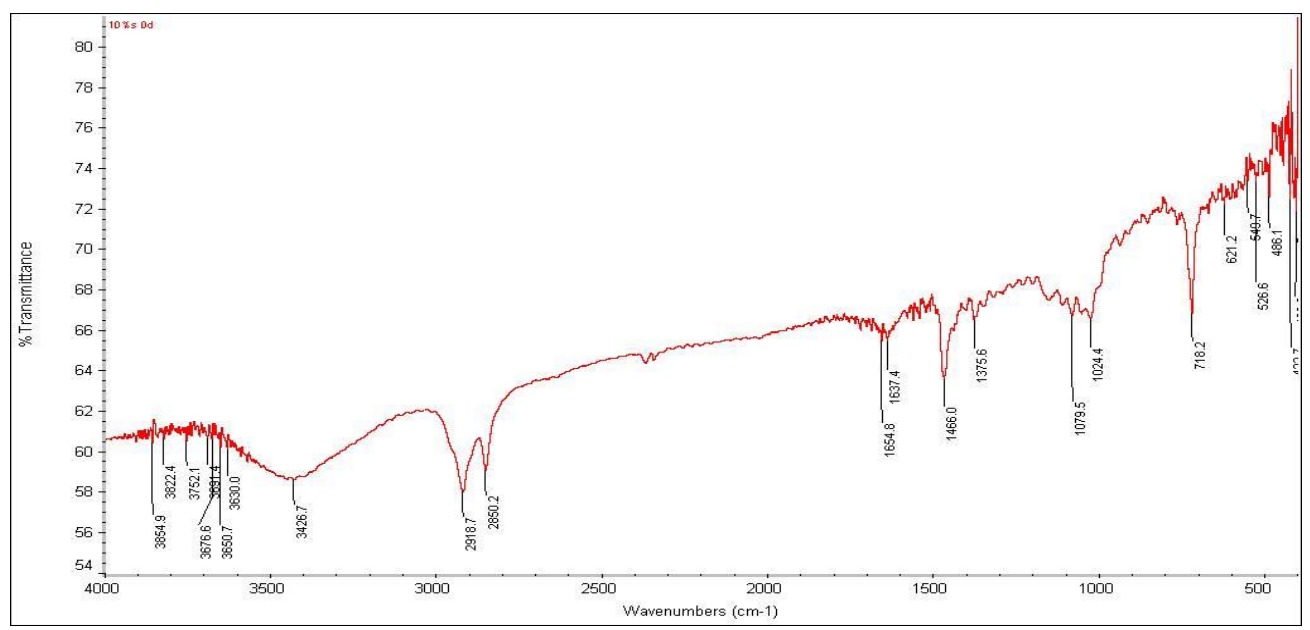

Figure 14: FTIR spectra for $10 \%$ starch at 0 day.

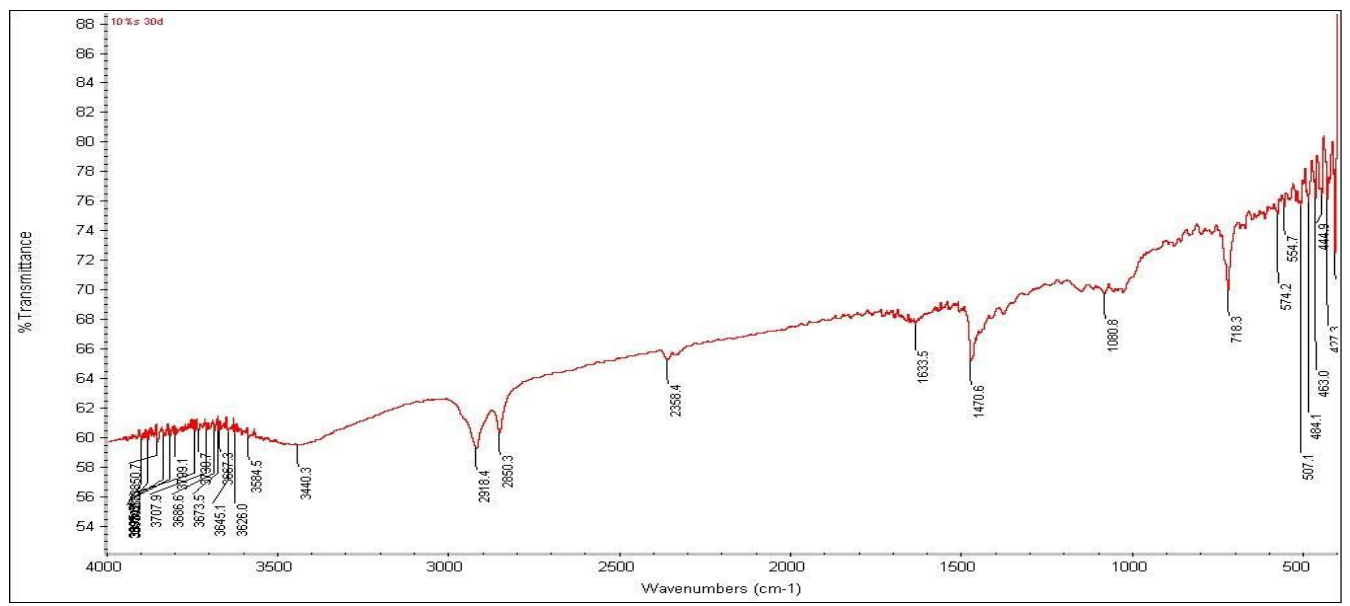

Figure 15: FTIR spectra for $10 \%$ starch after 30 days 


\subsection{SEM Analysis}

The SEM images for the polyethylene - starch blend (0\% starch , 5\% starch, 10\% starch, 15\% starch) taken at different exposure time ( 0,30 and 60 days) are presented in figures. Initially it's clear that there is no crack on the surface of the blend. When the time of exposure increases, degradation of the material starts and gradually the affected area increases. For the material after 30 days of exposure, initiation of cracks and degradation occurs; after 60 days of exposure, degradation propagates rapidly, bigger cracks are shown. This degradation is due to the degradation for the starch as well as for the oxidized the PE amorphous regions. Thereby, the surface area of polymer blends increases and this improves oxygen-based reactions that enhances and increases PE chain oxidation reaction.

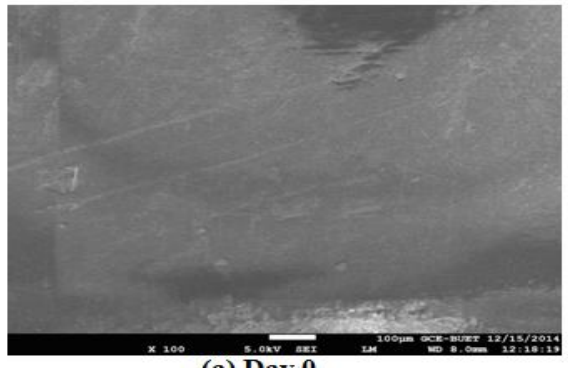

(a) Day 0

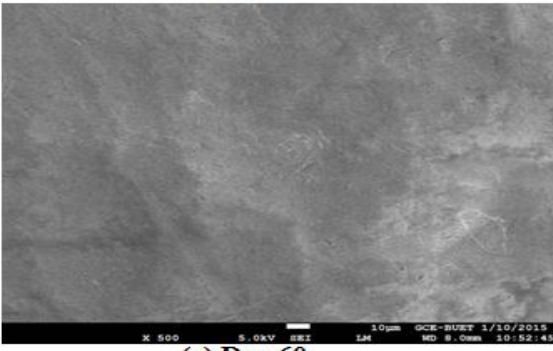

(c) Day 60

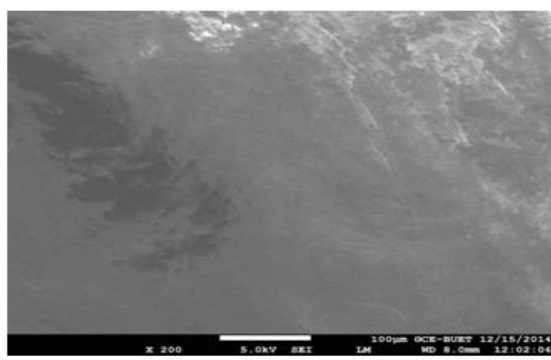

(b) Day30

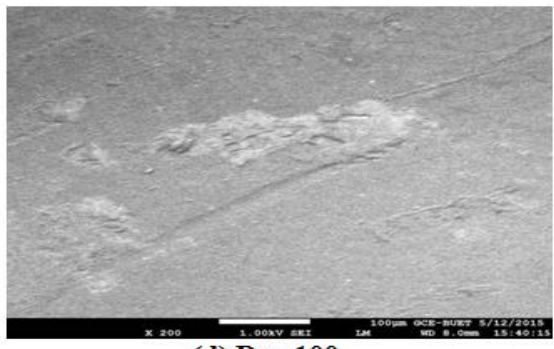

(d) Day 100

Figure 16 (a-d): SEM images of 0\% polyethylene-starch samples

Figure 16 (a-d) shows the surface images of $0 \%$ starch sample at different time intervals. From this figure it can be interpreted that there is no crack on the surface of the sample at 0 day and same smooth surfaces are also shown after 30 and 60 days of exposure. For later days, cracks seem to have developed and the surface is no longer smooth as on Day 0.

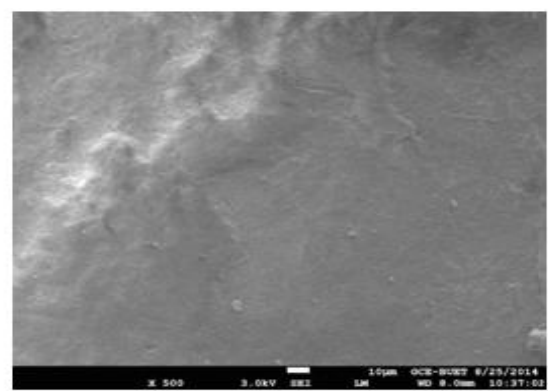

(a) At 0 day

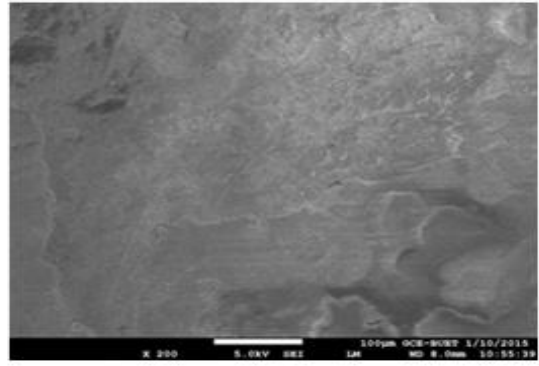

(c) Day 60

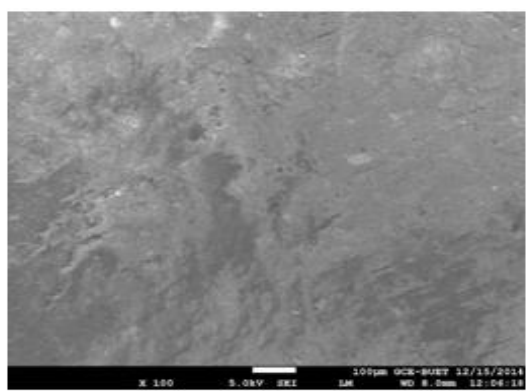

(b) after 30 days

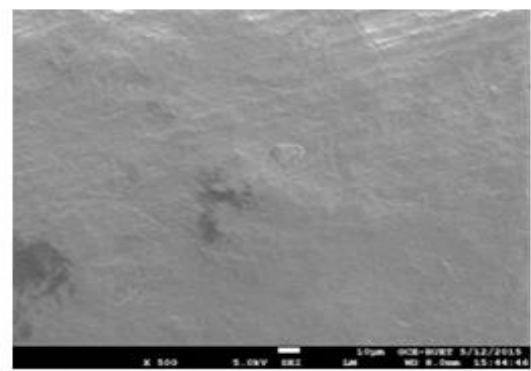

(d) Day 90

Figure 17 (a-d): SEM images of 5\% polyethylene-starch samples 
Figure 17(a-d) shows the surface images of 5\% starch sample at different time intervals. These images clearly indicate that with the increase of exposure days, the surface cracking of the sample increases gradually due to photo-degradation. At 0 day, the surface of blend sample is smooth without any cracking. After 30 days of exposure, the image shows the initiation of cracking on the surface. The surface cracking becomes bigger after 60 days of exposure.

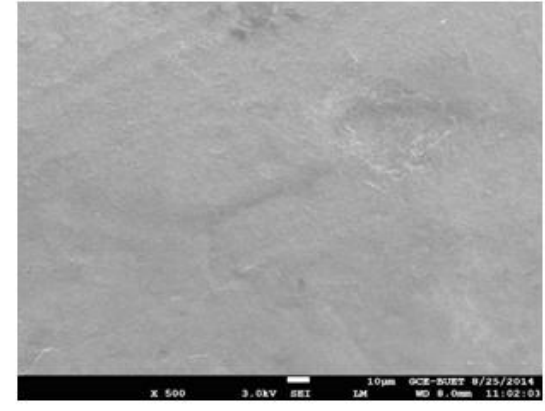

(a) Day 0

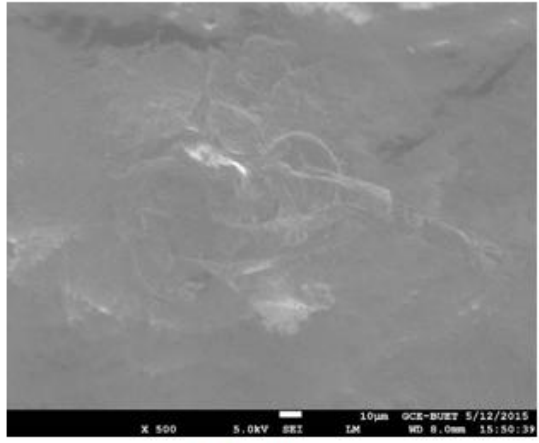

(c) Day 60

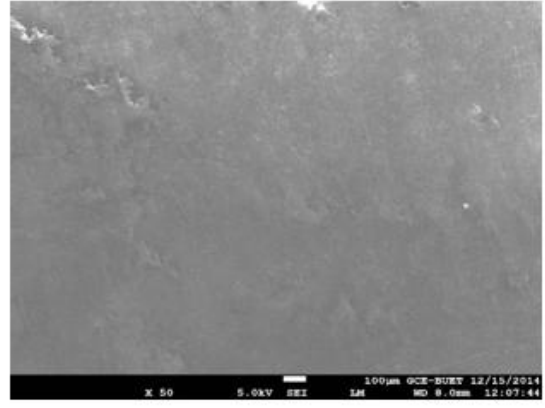

(b) Day 30

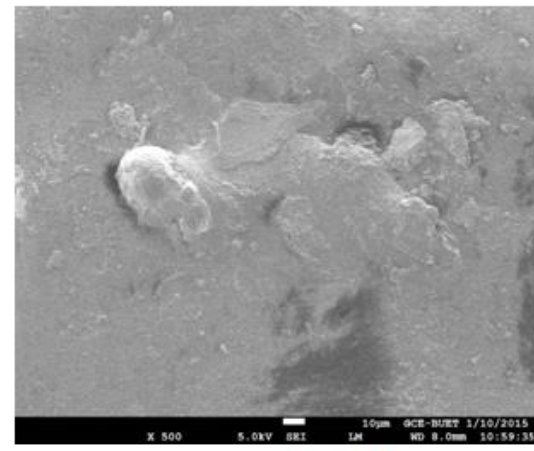

(d) Day 90

Figure 18 (a-d): SEM images of 10\% polyethylene-starch samples

Figure 18(a-d) shows the surface images of $10 \%$ starch sample at different time intervals. These images clearly indicate that with the increase of exposure days, the surface cracking of the sample increases gradually. At 0 day, the surface of blend sample is so smooth without any cracking. After 30 days of exposure, the image shows the initiation of cracking on the surface. The surface becomes rougher after 200 days of exposure.

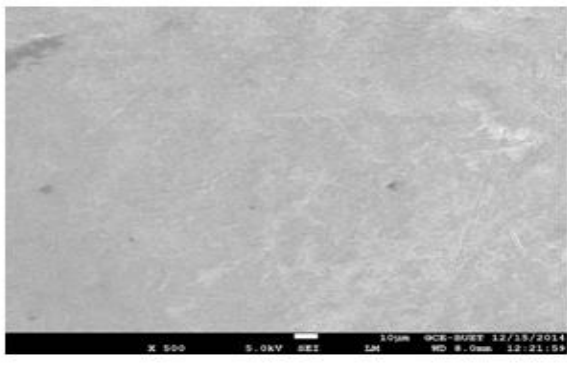

(a) Day 0

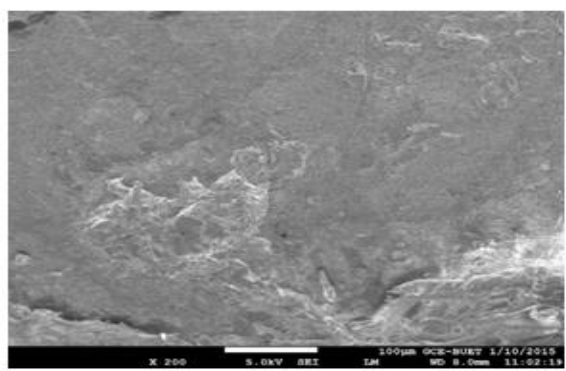

(c) Day 60

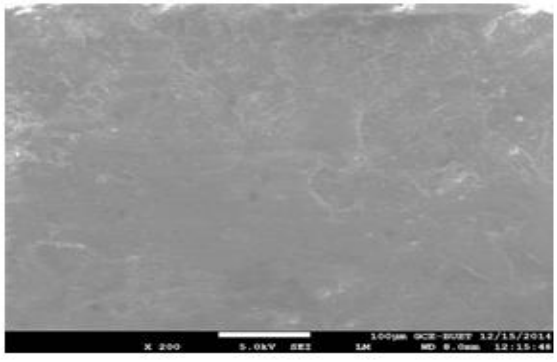

(b) Day 30

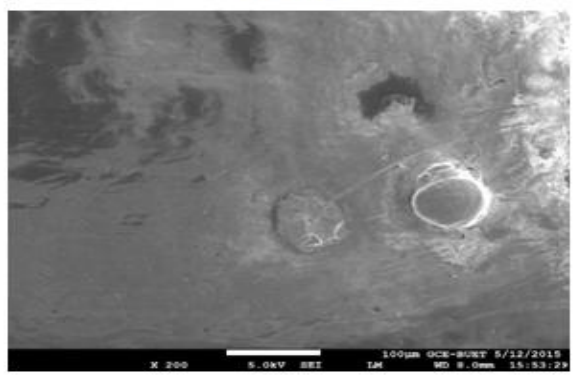

(d) Day 90

Figure 19 (a-d): SEM images of $15 \%$ polyethylene-starch samples 
Figure 19(a-d) shows the surface images of $15 \%$ starch sample at different time intervals. These images clearly indicate that with the increase of exposure days, the surface cracking of the sample increases gradually. At 0 day, the surface of blend sample is so smooth without any cracking. After 30 days of exposure, the image shows a very little change on the surface. The surface cracking becomes bigger after 200 days of exposure.

\subsection{Tearing Observations for the PE-Starch Films}

The following pictures depict the biodegradability of the films in terms of the force required to tear apart the films.

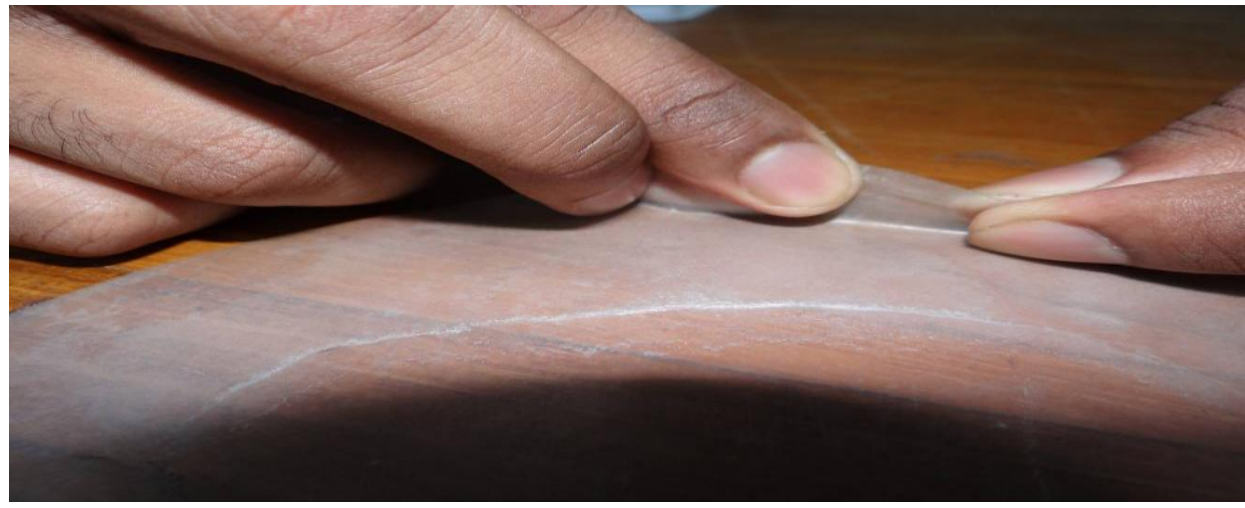

Figure 20: 0\% Starch-PE Film Resistant to Tear

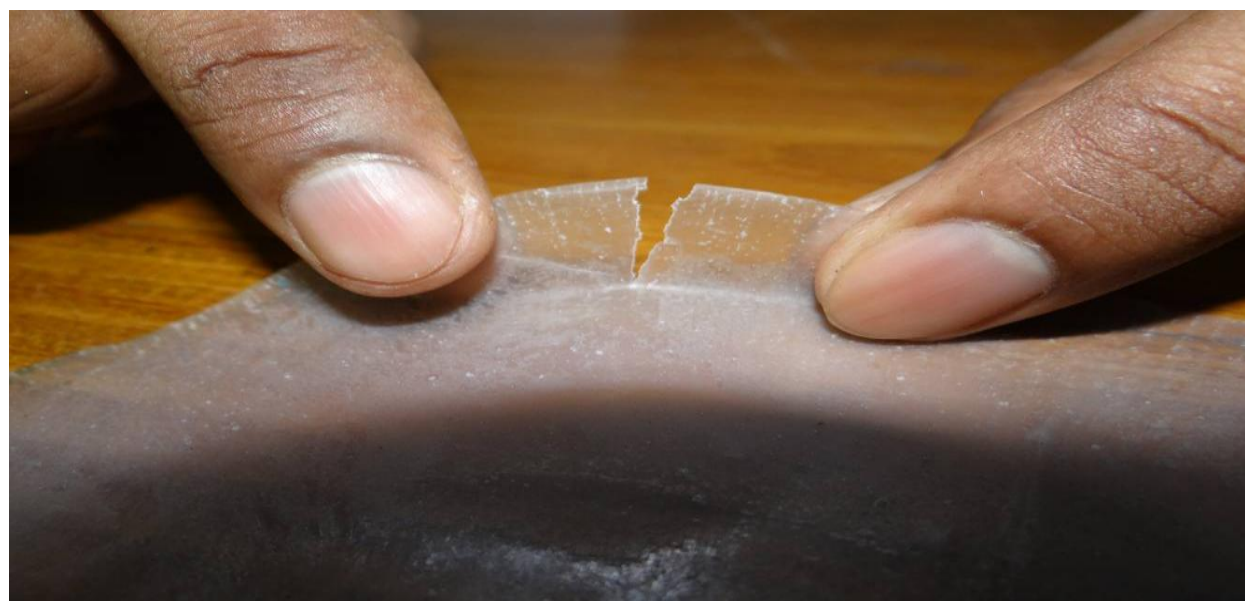

Figure 21: 10\% Starch-PE Film Easier to Tear

\section{Conclusion}

Blending of food grade corn starch with PE was planned with the aim of making the waste PE films biodegradable. Various combinations of different starch concentrations ranging from 0 to $15 \%$ in PE were blended and converted into plates and films. The specimens were studied for various properties like physico mechanical, morphological, chemical, etc., for packaging applications.

The mechanical properties show the drastic fall in tensile and flexural strength upon exposure. Brittleness and stiffness of the specimens was evident from the rise in the E-Modulus after exposure. FTIR of the samples revealed breakdown of the polyethylene to multiple compounds by breaking bonds. SEM study revealed that $\mathrm{PE} / \mathrm{starch}$ systems showed corroded morphology. The extruded films show degradation of the structure indicating biodegradability in both UV radiation and under microbial action.

All of these results prove the successful synthesis of a starch-polyethylene composite suitable for making biodegradable plastics, in particular for making waste PE biodegradable as well as for packaging materials and shopping bags to reduce their environmental impact.

\section{References}

[1]. Allen NS, Adge M, Houldsworth D, Rahman A, Catalina F, Fontan E, et al. Ageing and spectroscopic properties of polyethylenes: comparison with metallocene polymer. Polym Degrad Stab 2000;67:57-67.

[2]. Abdelkader Dehbi a,b,*, Amar Bouaza a, Ahmed Hamou b, Boulos Youssef c, Jean Marc Saiter c Materials and Design 31 (2010) 864-869.

[3]. Allen NS, Adge M, Houldsworth D, Rahman A, Catalina F, Fontan E, et al. Ageing and spectroscopic properties of polyethylenes: comparison with metallocene polymer. Polym Degrad Stab 2000;67:57-67. 
[4]. Anne-Charlotte Eliasson (2004). Starch in food: Structure, function and applications. Woodhead Publishing.

[5]. Benedict CV, Cook WJ, Jarrett P, Cameron JA, Huang SJ, Bell JP. Fungal degradation of polycaprolactones. Journal of Applied Polymer Science 1983;28:327-34.

[6]. Benedict CV, Cook WJ, Jarrett P, Cameron JA, Huang SJ, Bell JP. Fungal degradation of polycaprolactones. Journal of Applied Polymer Science 1983;28:327-34.

[7]. Billingham, N. C., M. Bonora and D. De Corte (2002), Environmental degradable plastics based on oxo-degradation of conventional polyolefins,

[8]. Billingham, N. C.; Wiles, D. M.; Cermak, B. E.; Gho, J. G.; Hare, C. W. J.; Tung, J. F. (2000), "Controlled-lifetime environmentally degradable plastics based on conventional polymers" Addcon World 2000, Two-Day Conference, 6th, Basel, Switzerland, Oct. 25-26, 2000 paper16/1-paper16/6. Publisher: Rapra Technology Ltd., Shrewsbury, UK.biodegradable plasticpoly-beta-hydroxybutyrate/polycaprolactone blend polymer." Kobunshi

[9]. Briassoulis D. Mechanical behavior of biodegradable agricultural films under real field conditions. Polym Degrad Stab 2006;91:1256-72.

[10]. Brown, W. H.; Poon, T. (2005), Introduction to organic chemistry (3rd ed.), Wiley

[11]. Chandra R, Rustgi R. Polym Degrad Stab 1997;56:185.

[12]. Chiellini, E. and R. Solaro (1996). Advanced Materials 8(305).

[13]. Chiellini, E., A. Corti and G. Swift (2003). "Biodegradation of thermally-oxidised, fragmented low- density polyethylene." Polymer Degradation and Stability 81(341).

[14]. Chiellini, Emo; Corti, Andrea. (2003), "A simple method suitable to test the ultimate biodegradability of environmentally degradable polymers". Macromolecular Symposia 197(7th World Conference on Biodegradable Polymers \& Plastics, 2002), 381395.

[15]. Cimmino, A.; Conte, C.; Incitti, S. (1991), "Biodegradability of plastic bags: chemical and regulatory aspectsRassegna Chimica 43(3), 109-16. copolyesters containing aromatic constituents." Polymer Degradation and Stability 59(1-3)203.

[16]. Cowie, J.M.G.; Arrighi, V. Polymers: Chemistry and Physics of Modern Materials, 3rd ed. CRC Press, 2008.

[17]. David R. Lineback, "Starch", in AccessScience@McGraw-Hill. 